\title{
Exercise induced upregulation of glutamate-cysteine ligase catalytic subunit and glutamate-cysteine ligase modifier subunit gene expression in Thoroughbred horses
}

\author{
Jeong-Woong Park', Jae-Young Choi ${ }^{1}$, Seul A Hong ${ }^{1}$, Nam Young Kim², Kyoung-Tag Do ${ }^{3}$, \\ Ki-Duk Song ${ }^{4, *}$, and Byung-Wook Cho ${ }^{1, *}$
}

\author{
* Corresponding Authors: Ki-Duk Song \\ Tel: +82-63-219-5523, Fax: +82-63-270-5937; \\ E-mail: kiduk.song@gmail.com \\ Byung-Wook Cho \\ Tel: +82-55-350-5515, Fax: +82-55-350-5519; \\ E-mail: bwcho@pusan.ac.kr \\ ${ }^{1}$ Department of Animal Science, College of Natural \\ Resources and Life Sciences, Pusan National \\ University, Miryang 50463, Korea \\ ${ }^{2}$ National Institute of Animal Science, Rural \\ Development Administration, Jeju 63242, Korea \\ ${ }^{3}$ Department of Animal Biotehnology, Faculty of \\ Biotechnology, Jeju National University, Jeju 63243, \\ Korea \\ ${ }^{4}$ Department of Animal Biotechnology, Chonbuk \\ National, University, Jeonju 54896, Korea
}

Submitted Oct 8, 2016; Revised Nov 6, 2016; Accepted Dec 29, 2016
Objective: This study was performed to reveal the molecular structure and expression patterns of horse glutamate-cysteine ligase catalytic subunit (GCLC) and glutamate-cysteine ligase modifier subunit (GCLM) genes whose products form glutamate cysteine ligase, which were identified as differentially expressed genes in the previous study.

Methods: We performed bioinformatics analyses, and gene expression assay with quantitative polymerase chain reaction (qPCR) for horse GCLC and GCLM genes in muscle and blood leukocytes of Thoroughbred horses

Results: Expression of GCLC showed the same pattern in both blood and muscle tissues after exercise. Expression of GCLC increased in the muscle and blood of Thoroughbreds, suggesting a tissue-specific regulatory mechanism for the expression of GCLC. In addition, expression of the GCLM gene increased after exercise in both the blood and muscle of Thoroughbreds. Conclusion: We established the expression patterns of GCLC and GCLM in the skeletal muscle and blood of Thoroughbred horses in response to exercise. Further study is now warranted to uncover the functional importance of these genes in exercise and recovery in racehorses.

Keywords: Horse; Exercise; Glutamate-cysteine Ligase Catalytic Subunit (GCLC); Glutamatecysteine Ligase Modifier Subunit (GCLM); Quantitative Polymerase Chain Reaction

\section{INTRODUCTION}

The aerobic respiration of muscle tissue is an important process in mammals. In steady-state muscle tissue, as part of the ATP generation mechanism during aerobic respiration, cytochrome $c$, an essential component of the electron transport system, stabilizes cells that are reacting with oxygen [1]. During rapid exercise, an oversupply of oxygen in the blood reacts with electrons that are generated from the electron transport system and forms reactive oxygen species (ROS) [2]. These ROS, which indicate oxidative stress, destroy DNA through muscle fatigue, damage, and apoptosis [3]. The protection of cellular organelles from ROS occurs in part via the oxidation of glutathione by ROS. The glutamate-cysteine ligase modifier subunit (GCLM) and the glutamate-cysteine ligase catalytic subunit $(G C L C)$ form the glutathione cysteine ligase $(G C L)$ that catalyzes the conversion of glutamate and cysteine into $\gamma$-glutamyl cysteine, a glutathione precursor [4]. During strenuous exercise and in other situations that induce oxidative stress, the GCLC gene is expressed [5,6]. In experiments using blood from marathon runners, glutathione expression was found to increase after strenuous exercise, and it has been hypothesized that GCLC was up-regulated in response to this exercise [7]. In the case of GCLM, the expression pattern also increased during strenuous exercise [6], again owing to oxidative stress [8]. A previous study 
showed that the expression of the GCLC and GCLM genes was up-regulated in the muscle of Thoroughbred horses in response to exercise [9]. These data indicate that glutathione-synthesisrelated genes play important roles in alleviating the stress response during exercise. Despite various experiments with GCLC and $G C L M$, understanding these genes in horses during exercise is still insufficient.

In this study, we performed bioinformatic analyses of horse GCLC and GCLM genes, and investigated their expression in muscle and blood in response to exercise stress to gain insights into their potential application as biomarkers for ROS responses in horses.

\section{MATERIALS AND METHODS}

\section{Tissue sampling}

Two stallions and one mare Throughbred horses aged 5, 9, and 10, weighing from 500 to $700 \mathrm{~kg}$ which were maintained at Ham-an Racing Horse Resort and Training Center were used to obtain the blood and skeletal muscle samples before and after exercise. Exercise was performed by trotting at the speed of $13 \mathrm{~km} / \mathrm{h}$ for $30 \mathrm{~min}$ and cantering through lunging and long-reining (circular bridge lunging).

Three Jeju horses ( 3 mares), which were maintained at The National Institute of Subtropical Agriculture, Rural Development Administration were used to obtain tissue samples skeletal muscle, kidney, thyroid, lung, appendix, colon, spinal cord and heart. All tissue samples were kept in a liquid nitrogen tank until extraction of RNA was done. All procedures were conducted by following the protocol that had been reviewed and approved by the Institutional Animal Care and Use Committee at Pusan National University (protocol numbers: PNU-2013-0417, PNU2013-0411).

\section{Total RNA isolation}

Total RNA samples for investigation of GCLC and GCLM gene expression were collected from three Thoroughbreds. Skeletal muscle, kidney, heart, liver, lung, colon, and spinal cord tissues were extracted for polymerase chain reaction (PCR) analysis. The various tissues sampled from the horses (50 to $100 \mathrm{mg}$, or $3 \mathrm{~mL}$ in the case of blood) were crushed with a mortar and pestle and mixed with $9 \mathrm{~mL}$ of red blood cell lysis buffer (Solgent Co. Ltd., Daejeon, Korea) to remove red blood cells. The cells were then dissolved using $1 \mathrm{~mL}$ of TRIzol (Invitrogen, Karlsruhe, Germany), and $200 \mu \mathrm{L}$ of chloroform was added to remove cells from the organic solvent. The mixture was then shaken for 10 $s$ and left at $4^{\circ} \mathrm{C}$ for $5 \mathrm{~min}$. Centrifugal separation was carried out at $4^{\circ} \mathrm{C}$ for $15 \mathrm{~min}$, and then the supernatant was removed to a new test tube and mixed with the same amount of isopropanol. The test tube was left at $4^{\circ} \mathrm{C}$ for $15 \mathrm{~min}$ to produce RNA pellets. Isopropanol was removed by carrying out centrifugal separation at $4^{\circ} \mathrm{C}$ for $15 \mathrm{~min}$ and the sample was then sterilized with $85 \%$ ethanol and dissolved in RNase-free water. The purity of the extracted RNA was confirmed by measuring the absorbance at $230 \mathrm{~nm}$ and $260 \mathrm{~nm}$ using a spectrophotometer (ND-100, Nano Drop Technologies Inc., Wilmington, DE, USA), and only the extracted RNA with purity optic density (OD) value at 230 $\mathrm{nm}$ divided by OD value at $260 \mathrm{~nm}$ ) over 1.8 (found via quantitative analysis) was used. The selected RNA was stored at $-70^{\circ} \mathrm{C}$ until the experiment was performed.

\section{cDNA synthesis}

In order to synthesize cDNA, $2 \mu \mathrm{g}$ of RNA, $1 \mu \mathrm{L}$ of oligo-dT (Invitrogen, Germany), and $1 \mu \mathrm{L}$ of RNase-free water were added, the mixture was denatured at $80^{\circ} \mathrm{C}$ for $3 \mathrm{~min}$, and then the cDNA was synthesized using $4 \mu \mathrm{L}$ of $5 \times$ reverse transcription buffer, $5 \mu \mathrm{L}$ of $2 \mathrm{mM}$ deoxynucleotides (dNTPs), $0.5 \mu \mathrm{L}$ of RNase inhibitor (Promega Corporation, Madison, WI, USA), and $1 \mu \mathrm{L}$ of moloney murine leukemia virus reverse transcriptase (Promega, USA).

\section{Polymerase chain reaction}

The nucleotide sequences of horse GCLC and GCLM genes from the National Center for Biotechnology Information (http://www. ncbi.nlm.nih.gov) and the Ensembl Genome Browser (http:// www.ensembl.org) were retrieved to design the primers with PRIMER3 software (http://bioinfo.ut.ee/primer3-0.4.0/). The primers sequences of horse GCLC and GCLM genes were as followed: GCLC forward 5'-ACCAGGGTGATCCTGTCGTA-3' and reverse $5^{\prime}$-ATCCCGTTTCTGTGCGACTT- ${ }^{\prime}$ ', and GCLM forward $5^{\prime}$-GTG TGA TGC CAC CTG ATT TG-3' and reverse 5'-GCT TTT CAC GAT GAC CGA GT-3'. The PCR to amplify the target genes on the cDNA was carried out under the following conditions: $1.8 \mu \mathrm{L}$ dNTP, $2 \mu \mathrm{L} 10 \times$ buffer, $0.2 \mu \mathrm{L}$ HS-Taq, and $12 \mu \mathrm{L}$ distilled water were added to $2 \mu \mathrm{L}, 50 \mathrm{ng} / \mu \mathrm{L}$ diluted DNA and $5 \mathrm{pmol} / \mu \mathrm{L}$ diluted forward primer and reverse primer. The PCR was carried out in a total volume of $20 \mu \mathrm{L}$. The PCR procedure was: denaturation at $94^{\circ} \mathrm{C}$ for $10 \mathrm{~min}$, and a second denaturation at $94^{\circ} \mathrm{C}$ for $30 \mathrm{~s}$, followed by annealing at $58^{\circ} \mathrm{C}$ for $30 \mathrm{~s}$, and extension at $72^{\circ} \mathrm{C}$ for $30 \mathrm{~s}$. This was repeated for 40 cycles, and then a final extension was performed at $72^{\circ} \mathrm{C}$ for $10 \mathrm{~min}$. The band was confirmed on UV using a 1.5\% SeaKem LE agarose gel (Lonza, Rockland, MD, USA).

\section{Real time quantitative polymerase chain reaction amplification}

The real time quantitative polymerase chain reaction (RT-qPCR) was performed using a C1000 Thermal Cycler (Bio Rad, Hercules, CA, USA) in order to measure the relevant expression of the target genes. A reaction solution of $25 \mu \mathrm{L}$ was used and the solution was prepared as follows: $2 \mu \mathrm{L}$ and $5 \mu \mathrm{L}$ of distilled water, and 2 $\mu \mathrm{L}$ of diluted cDNA ( $50 \mathrm{ng} / \mu \mathrm{L}$ ) were added to $14 \mu \mathrm{L}$ of SYBR green master mix (Bio Rad, USA), along with $5 \mathrm{pmol} / \mu \mathrm{L}$ each of diluted forward primer and reverse primer. The RT-qPCR 
conditions were as follows: the first denaturation was carried out at $94^{\circ} \mathrm{C}$ for $10 \mathrm{~min}$, and then the second denaturation was at $94^{\circ} \mathrm{C}$ for $10 \mathrm{~s}$; the annealing occurred at $60^{\circ} \mathrm{C}$ for $10 \mathrm{~s}$, followed by an extension at $72^{\circ} \mathrm{C}$ for $30 \mathrm{~s}$. This was carried out repeatedly 40 times. All measurements were performed in triplicate for all specimens, and the comparative method used was the $2^{-\Delta \Delta \mathrm{Ct}}$ method [10]. The relevant expression of the target genes was calculated using glyceraldehyde-3-phosphate dehydrogenase (GAPDH) as a normalizer.

\section{Phylogenetic analysis}

The amino acid sequences of GCLC and GCLM of various species were obtained from National Center for Biotechnology Information (NCBI): Amino sequence of GCLC was obtained with cow (NP_001077143.1), human (NP_001489.1), macaque (XP_ 005552782.1), mouse (NP_034425.1), orangutan (XP_002817060.1), rat (NP_036947.1), pig (XP_003482212.1), horse (XP_001503230.2) and cow (NP_001033232.1), human (NP_002052.1), macaque (NP_001270732.1), mouse (NP_032155.1), orangutan (XP_ 002810638.1), rat (NP_059001.1), pig (XP_001926413.1), horse (F6WKI2) was obtained for GCLM. Amino acids were aligned using Multiple Sequence Comparison by Log-Expectation (MUSCLE) (http://www.ebi.ac.uk/Tools/msa/muscle/). Phylogenetic analysis was performed using Neighbor-Joining method
[11] with pairwise deletion, 1,000 bootstrap replication, and Kimura 2 as described previously [12].

\section{Statistical analysis}

Both T-test and analysis of variance statistical test was conducted to determine significance levels. Data were shown by mean \pm standard error of mean.

\section{RESULTS AND DISCUSSION}

As human and mouse, horse GCLC and GCLM are encoded by different genes which are located in chromosome 20 and 16 respectively. The genomic structure of horse GCLC and GCLM is shown in (Figure 1). The GCLC gene consists of 16 exons, and the GCLM gene is composed of 6 exons. The full lengths of the GCLC and GCLM genes are 1,935 and 1,425 bp, respectively. The horse GCLC gene encodes 637 amino acids and the GCLM gene encodes 233 amino acids (Table 1 ).

To investigate the evolutionary relationships of GCLC and GCLM in horses, we obtained gene sequences from eight species of mammals (human, macaque, orangutan, cow, pig, horse, rat, and mouse) from Ensembl 62 and conducted a phylogenetic analysis (Figure 2). The amino acid similarity of the two genes in the eight mammals is over $90 \%$ (Tables 2, 3). Both horse GCLC

GCLC

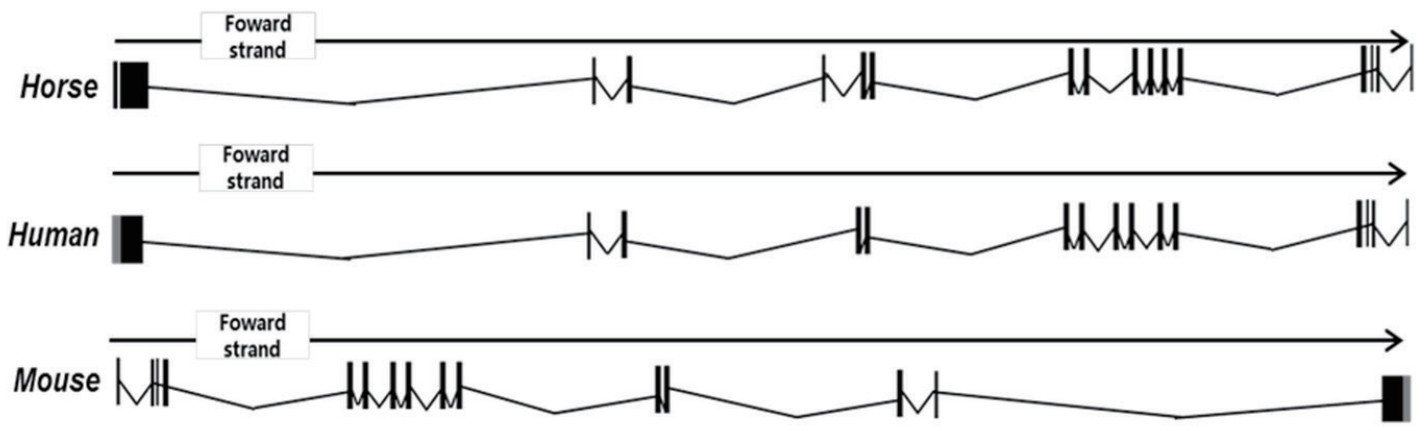

GCLM

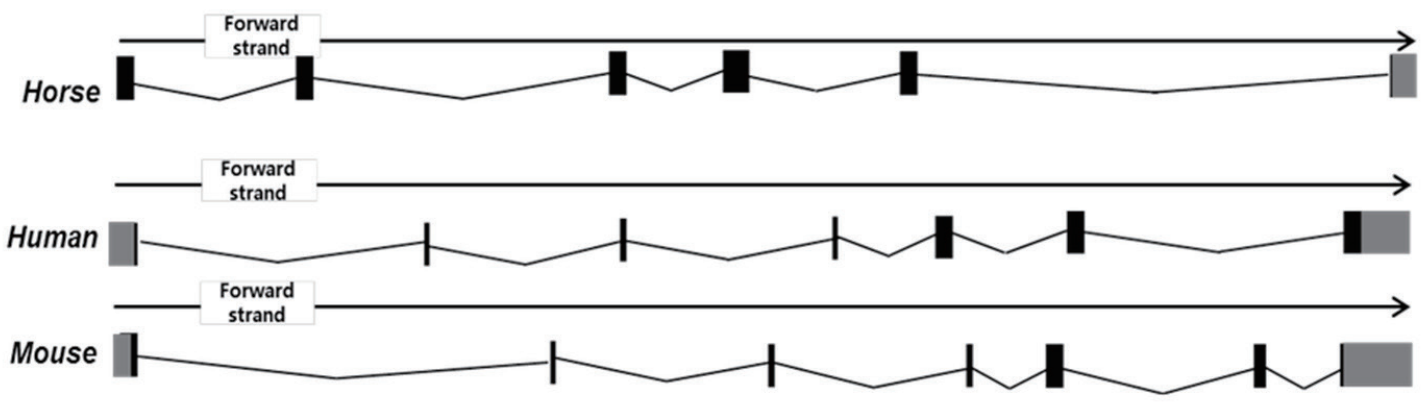

Figure 1. i) Gene structure of the glutamate-cysteine ligase catalytic subunit (GCLC) and glutamate-cysteine ligase modifier subunit (GCLM) genes in horses. (A) Gene structure of GCLC and GCLM. GCLC has 16 exons, and GCLM has 6 exons. Black boxes indicate exons, grey boxes indicate untranslated regions (UTR), and black lines indicate introns. 
(B)
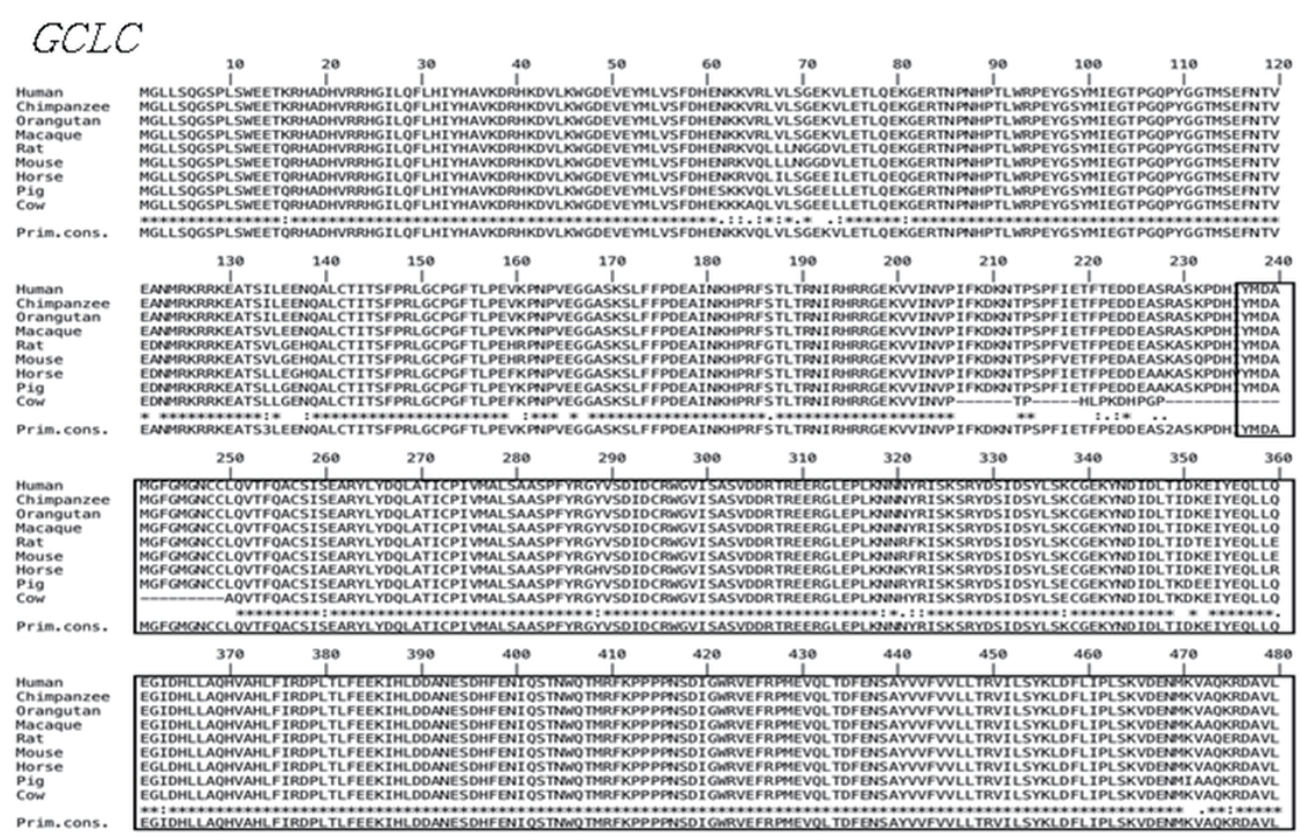

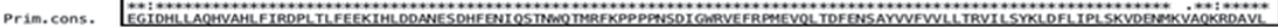
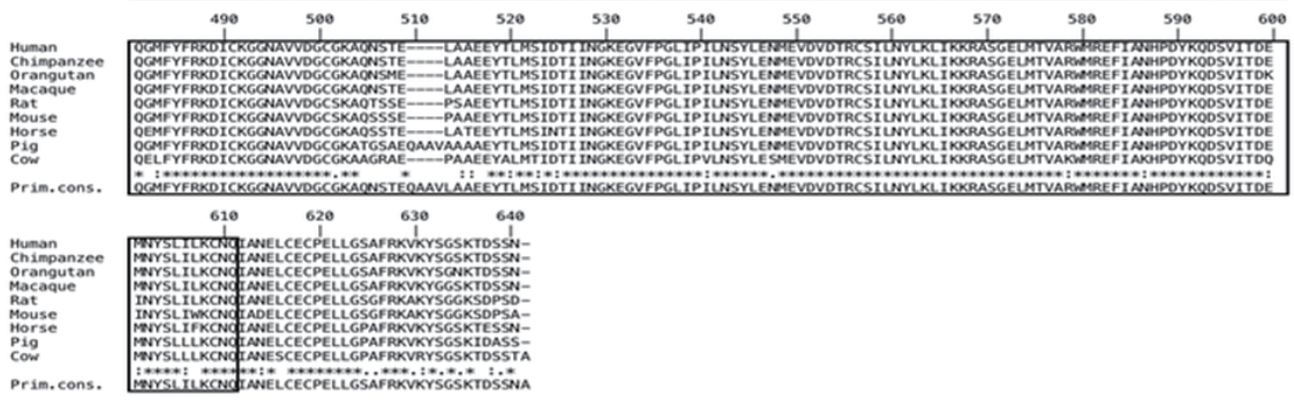

GCLM

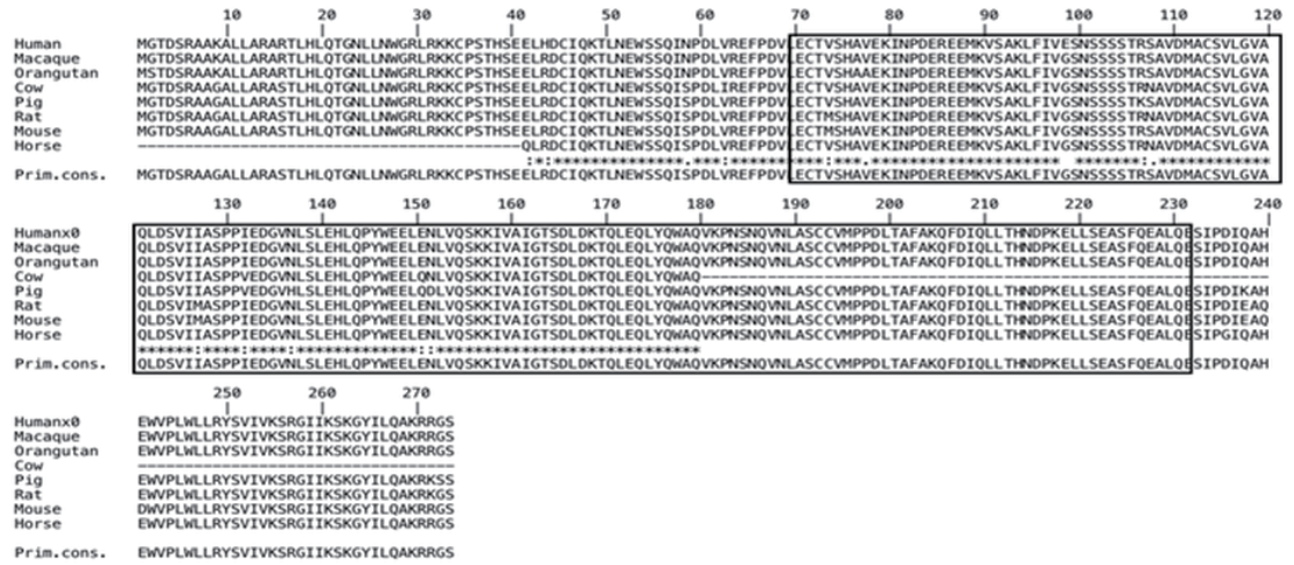

Figure 1. ii) Gene structure of the glutamate-cysteine ligase catalytic subunit (GCLC) and glutamate-cysteine ligase modifier subunit (GCLM) genes in horses (Continued). (B) Amino acid sequence alignment of GCLC and GCLM proteins with MUSCLE software (http://www.ebi.ac.uk/Tools/msa/muscle/).

and GCLM are clustered in the same clade as other livestock such as pig and cow. Simple modular architecture research tool (SMART) analysis revealed that horse GCLC protein contains the gammaglutamylcysteine synthetase (GCS) domain from amino acid position 236 to 608 , which represents a signature catalytic subunit of glutamate-cysteine ligase domain (EC 6.3.2.2) (Figure 1B). Horse GCLM protein possess the aldo-keto reductase family domain which is covered by the amino acid sequences from 
Table 1. Genetic information for the glutamate-cysteine ligase catalytic subunit $(G C L C)$ and glutamate-cysteine ligase modifier subunit (GCLM) genes in horses

\begin{tabular}{llccc}
\hline Gene symbol & Location & Length (bp) & Length (aa) & Number of exons \\
\hline GCLC & Chr 20: $50,985,591-51,029,180$ & 1,935 & 637 & 16 \\
GCLM & Chr 5: $71,102,814-71,115,917$ & 1,425 & 233 & 6 \\
\hline
\end{tabular}

bp, base pair; aa, amino acid.

Table 2. Amino acid sequence identity of GCLC protein

\begin{tabular}{lcccccccc}
\hline & Cow & Rat & Mouse & Horse & Pig & Macaque & Orangutan & Human \\
\hline Cow & - & 90.58 & 90.74 & 92.73 & 94.21 & 92.89 & 93.06 & 93.06 \\
Rat & 90.58 & - & 98.27 & 92.46 & 93.41 & 94.19 & 94.19 & 94.19 \\
Mouse & 90.74 & 98.27 & - & 92.78 & 93.25 & 94.51 & 94.51 \\
Horse & 92.73 & 92.46 & 92.78 & - & 94.51 & 95.13 & 94.98 & 94.51 \\
Pig & 94.21 & 93.41 & 93.25 & 94.51 & - & 95.60 & 95.29 & 95.45 \\
Macaque & 92.89 & 94.19 & 94.51 & 95.13 & 95.60 & - & 99.06 \\
Orangutan & 93.06 & 94.19 & 94.51 & 94.98 & 95.29 & 99.06 & - & 99.37 \\
Human & 93.06 & 94.19 & 94.51 & 95.29 & 95.45 & 99.37 & 99.37 & - \\
\hline
\end{tabular}

GCLC, glutamate-cysteine ligase catalytic subunit.

Table 3. Amino acid sequence identity of GCLM protein

\begin{tabular}{lcccccccc}
\hline & Horse & Human & Orangutan & Macaque & Mouse & Rat & Pig & Cow \\
\hline Horse & - & 97.42 & 97.85 & 98.28 & 96.57 & 97.00 & 95.28 & 97.12 \\
Human & 97.42 & - & 98.54 & 99.27 & 96.35 & 95.99 & 95.26 \\
Orangutan & 97.85 & 98.54 & - & 99.27 & 96.35 & 95.99 & 95.26 \\
Macaque & 98.28 & 99.27 & 99.27 & - & 97.08 & 96.72 & 95.99 & 95.00 \\
Mouse & 96.57 & 96.35 & 96.35 & 97.08 & - & 98.91 & 95.62 & 96.11 \\
Rat & 97.00 & 95.99 & 95.99 & 96.72 & 98.91 & - & 95.99 \\
Pig & 95.28 & 95.26 & 95.26 & 95.99 & 95.62 & 95.99 & - & 97.22 \\
Cow & 97.12 & 95.00 & 95.00 & 96.11 & 96.67 & 97.22 & 97.22 & - \\
\hline
\end{tabular}

GCLM, glutamate-cysteine ligase modifier subunit.

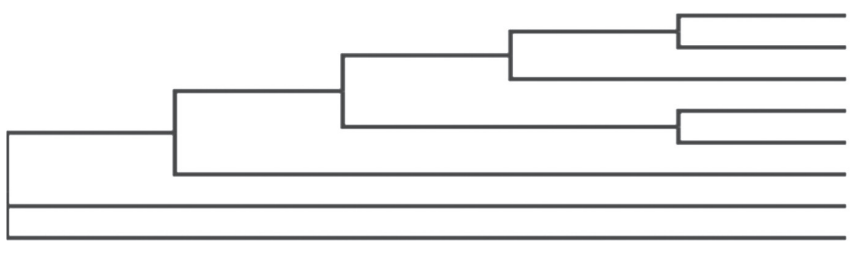

GCLM

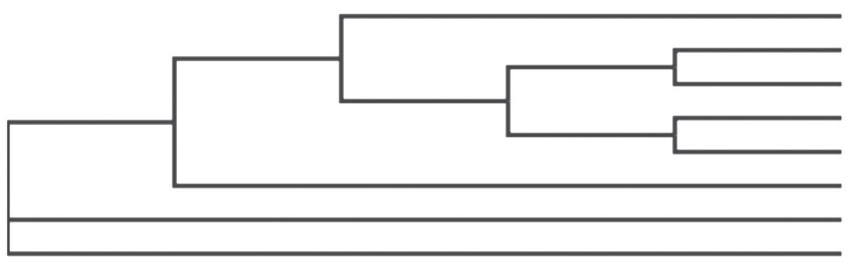

Cow 0.0407

Pig 0.01715

Horse 0.02773

Rat 0.00969

Mouse 0.00758

Macaque 0.00388

Orangutan 0.00417

Human 0.00211
Horse 0.00789

Mouse 0.00527

Rat 0.00568

Pig 0.01701

Cow 0.01077

Orangutan 0.00651

Human 0.00758

Macaque -0.00028

Figure 2. Unrooted phylogenetic trees for horse glutamate-cysteine ligase catalytic subunit (GCLC) genes and glutamate-cysteine ligase modifier subunit (GCLM) genes based on amino acid sequences. 
(A)
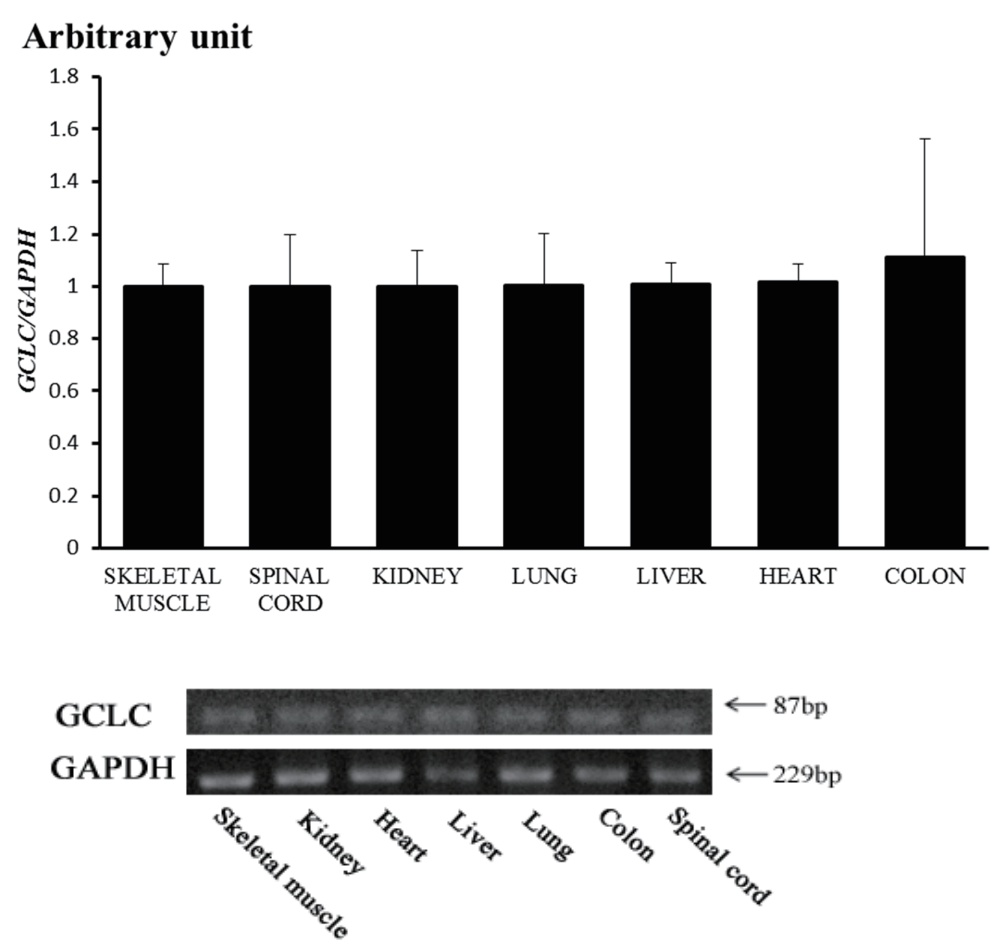

(B)

\section{Arbitrary unit}
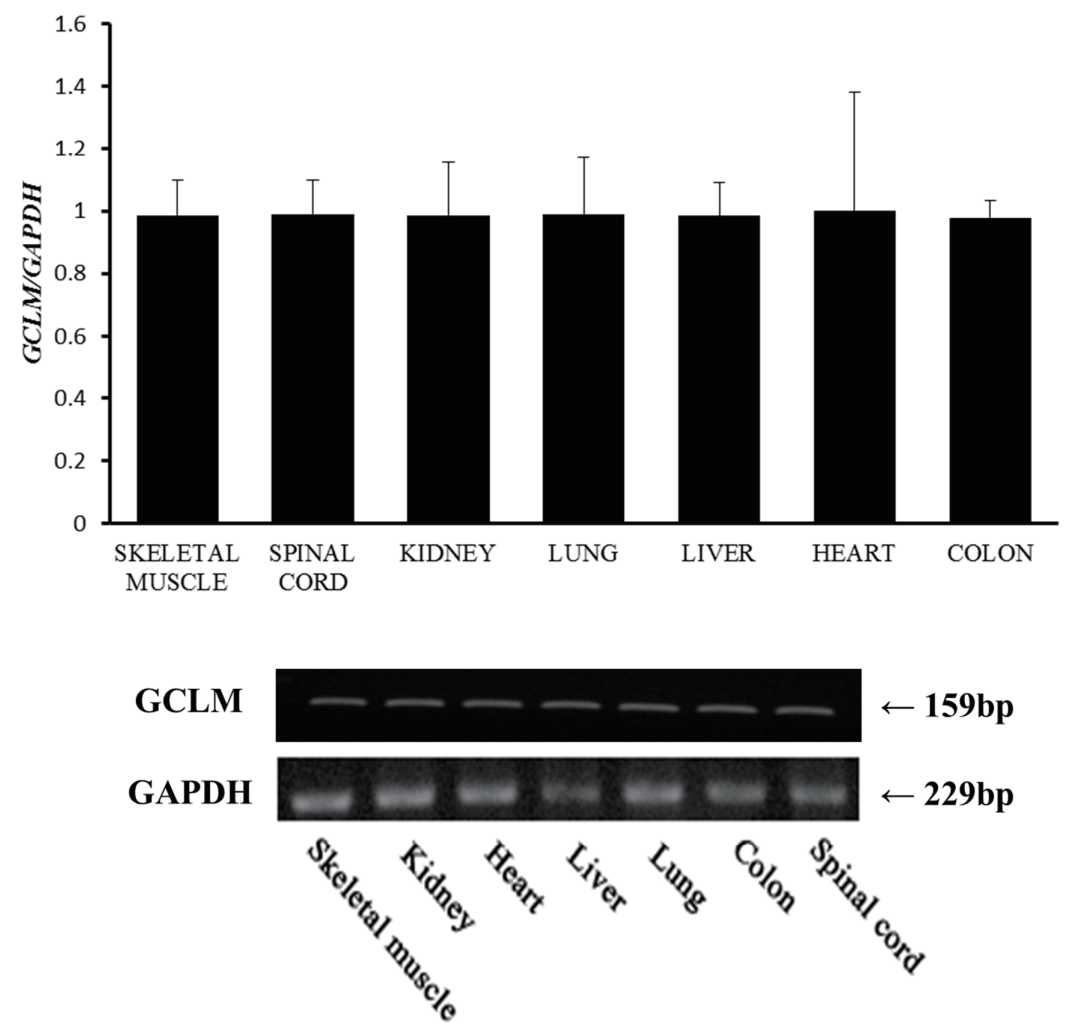

Figure 3. Expression of horse glutamate-cysteine ligase catalytic subunit (GCLC) gene (A), and glutamate-cysteine ligase modifier subunit (GCLM) gene (B) by RT-qPCR and RT-PCR. mRNA expressions were determined by real-time quantitative polymerase chain reaction analysis (RT-qPCR; top) and RT-PCR (bottom) in a variety of tissues from the Thoroughbred horse. Glyceraldehyde-3-phosphate dehydrogenase (GAPDH) was used for normalization. 
29 to 190 (Figure 1B). Taken together, these two proteins are structurally conserved, suggesting that the function of GCLC and GCLM are conserved during the evolution.

To get the insights for function of these genes, we conducted RT-PCR and RT-qPCR using seven Thoroughbred horse tissues (Figure 3). The results showed that GCLC and GCLM are expressed in skeletal muscle, kidney, heart, liver, lung, colon, and spinal cord, suggesting ubiquitous expression. But there were no differences in both of GCLC gene and GCLM gene expression in the horse tissues studied in this study (Figure 3). To reveal the relationship between exercise induced stress and transcriptional activity of glutathione synthesis related genes, we prepared total RNAs from skeletal muscle and blood of Thoroughbred horses and performed RT-qPCR analysis for GCLC and GCLM genes. As result, it was found that the expression of both of GCLM and GCLC genes was up-regulated in skeletal muscle as well as blood leukocytes.

The mRNA level of GCLC gene after exercise was about 10fold higher than that before exercise in skeletal muscle (Figure $4 \mathrm{~A}$ left; $\mathrm{p}<0.05$ ), whereas the degree of increase of mRNA level in blood leukocytes is less compared to skeletal muscle (Figure $4 \mathrm{~B}$ right; $\mathrm{p}<0.001)$. The level of mRNA of horse GCLM gene also increased in both skeletal muscle and blood leukocytes in response to exercise (Figure 4B). In either case, it is not clear whether the increased expression of mRNA of these genes is the consequences of increased transcription efficiency or post-transcriptional modifications, i.e., increased stability, and is also not certain whether increased mRNA level will result in increased protein level, leading to augmented GCL activity. In a previous study, GCLC contents and activity tended to increase with exercise in skeletal muscle of both old and adult rats with different kinetics, indicating differential regulation of GCLC content and activity. Nonetheless, in old rats, GCLM contents seemed to increase more but not in adult rats $[13,14]$. As the expression of GCLM and the association of GCLM with GCLC are responsible for the increase $G C L$ activity [15] and ROS rapidly activates $G C L$ activity by facilitating the holozyme formation [5], it is reasonable to assume that GCL might be activated in skeletal muscle and blood leukocytes of Thoroughbred horses in response to exercise stress to alleviate stress induced ROS.

\section{CONCLUSION}

In this study, we observed that amino acid sequences of GCLC and GCLM are highly conserved evolutionary and, especially, functional domains of GCS and aldo-keto reductase family domain are well conserved in horse proteins, suggesting functional conservation of these proteins. It is of note that the mRNA

(A)

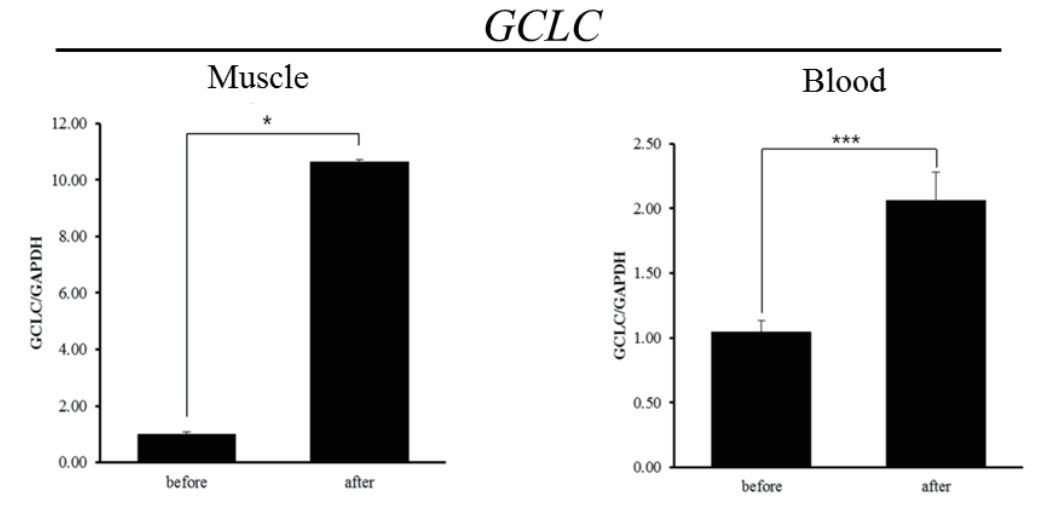

(B)

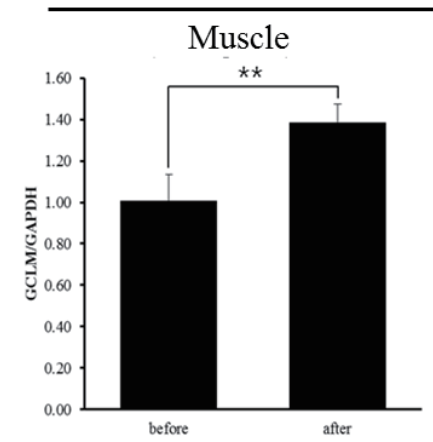

GCLM

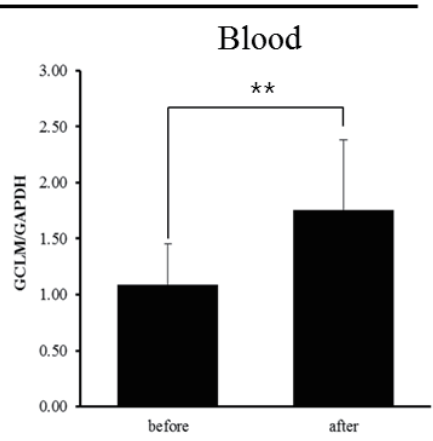

Figure 4. Expression of glutamate-cysteine ligase catalytic subunit $(G C L C)$ and glutamate-cysteine ligase modifier subunit (GCLM) genes determined by real-time quantitative polymerase chain reaction analysis (RT-qPCR) in horses before and 30 minutes after exercise. (A) Expression of the GCLC gene in muscle and blood leukocytes of Thoroughbred horses $\left(n=3,{ }^{*} p<0.5,{ }^{* *} p<0.001\right)$. (B) Expression of the GCLM gene in muscle and blood leukocytes of Thoroughbred horses ( ${ }^{* *} p<0.05$,). Quantitative analysis was performed using the $2^{-\Delta \Delta \mathrm{Ct}}$ method. Glyceraldehyde-3-phosphate dehydrogenase (GAPDH) was used for normalization. 
level of GCLC and GCLM gene is increased in both skeletal muscle and blood leukocytes in response to exercise. These results will provide the basic foundation for the future studies to reveal the importance of GCL activity to relieve ROS stress caused by exercise in racing horse, leading better interventions to racing stresses and the development of reliable non-invasive biomarkers for ROS responses.

\section{CONFLICT OF INTEREST}

We certify that there is no conflict of interest with any financial organization regarding the material discussed in the manuscript.

\section{ACKNOWLEDGMENTS}

This work was supported by a grant from the Next-Generation BioGreen 21 Program (No.PJ01104401, PJ01117301), Rural Development Administration, Republic of Korea, and research funds for newly appointed professors of Chonbuk National University in 2016 (K.D. Song).

\section{REFERENCES}

1. Couto N, Malys N, Gaskell SJ, Barber J. Partition and turnover of glutathione reductase from Saccharomyces cerevisiae: a proteomic approach. J Proteome Res 2013;12:2885-94.

2. Zhuo Y, Luo H, Zhang K. Leber hereditary optic neuropathy and oxidative stress. Proc Nat Acad Sci USA 2012;109:19882-3.

3. Powers SK, Kavazis AN, McClung JM. Oxidative stress and disuse muscle atrophy. J Appl Physiol 2007;102:2389-97.

4. Nava GM, Lee DY, Ospina JH, Cai SY, Gaskins HR. Genomic analyses reveal a conserved glutathione homeostasis pathway in the invertebrate chordate Ciona intestinalis. Physiol Genomics 2009;39:183-94.

5. Krejsa CM, Franklin CC, White CC, et al. Rapid activation of glutamate cysteine ligase following oxidative stress. J Biol Chem 2010;285:
16116-24

6. Muthusamy VR, Kannan S, Sadhaasivam K, et al. Acute exercise stress activates Nrf2/ARE signaling and promotes antioxidant mechanisms in the myocardium. Free Rad Biol Med 2012;52:366-76.

7. Lee KY, Kim SJ, Cha YS, et al. Effect of exercise on hepatic gene expression in an obese mouse model using cDNA microarrays. Obesity 2006;14:1294-302.

8. Solis WA, Dalton TP, DieterM Z, et al. Glutamate-cysteine ligase modifier subunit: mouse Gclm gene structure and regulation by agents that cause oxidative stress. Biochem Pharmacol 2002;63: 1739-54.

9. Park W, Kim J, Kim HJ, et al. Investigation of de novo unique differentially expressed genes related to evolution in exercise response during domestication in thoroughbred race horses. PloS one 2014;9: e91418.

10. Livak KJ, Schmittgen TD. Analysis of relative gene expression data using real-time quantitative PCR and the $2^{-\triangle \triangle C T}$ method. Methods 2001;25:402-8.

11. Saitou N, Nei M. The neighbor-joining method: a new method for reconstructing phylogenetic trees. Mol Biol Evol 1987;4:406-25.

12. Cho HW, Shin S, Park JW, et al. Molecular characterization and expression analysis of the peroxisome proliferator activated receptor delta (PPAR $\delta$ ) gene before and after exercise in horse. Asian-Australas J Anim Sci 2015;28:697-702.

13. Chen CNJ, Brown-Borg HM, Rakoczy SG, Thompson LV. Muscle disuse: adaptation of antioxidant systems is age dependent. J Gerontol A Biol Sci Med Sci 2008;63:461-6.

14. Chen CNJ, Brown-Borg HM, Rakoczy SG, Ferrington DA, Thompson LV. Aging impairs the expression of the catalytic subunit of glutamate cysteine ligase in soleus muscle under stress. J Gerontol A Biol Sci Med Sci 2010;64A:129-37.

15. Lee JI, Kang J, Stipanuk MH. Differential regulation of glutamatecysteine ligase subunit expression and increased holoenzyme formation in response to cysteine deprivation. Biochem J 2006;393:181-90. 